\title{
Dynamic analysis of a class of neutral delay model based on the Runge-Kutta algorithm
}

\author{
Hongying Luo
}

\begin{abstract}
In this paper, we study the dynamics of a class of second-order neutral delay nonlinear models. This study is applicable to many fields, such as engineering, cybernetics, and physics. We use the Runge-Kutta algorithm and the Riccati transform method. First, we give a neutral delay nonlinear model based on the Runge-Kutta algorithm. Then, we study the dynamic characteristics of the neutral delay model and establish some new sufficient conditions for the oscillation. The results of our research are new, and these results promote and improve the results already available. The results are also verified by numerical experiments. The neutral delay nonlinear model has an important application in engineering, cybernetics, and physics. Therefore, the study of this paper has great help and promotion to engineering, cybernetics, and physics.
\end{abstract}

Keywords: Runge-Kutta algorithm, Neutral delay model, Dynamic analysis, Oscillation

\section{Introduction}

The Runge-Kutta algorithm is a more practical algorithm built on the basis of mathematical support [1]. This algorithm is an important implicit or explicit iterative method for solving the solutions of nonlinear ordinary differential equations [2]. Because of the high precision of the algorithm, it is a kind of high-precision single-step algorithm widely used in engineering [3]. However, some measures need to be taken to suppress the deviation, so the implementation principle is more complex [4]. In recent years, due to the widespread application of neutral delay differential equations in engineering cybernetics and physics fields, a wide range of attention has been drawn from scholars both at home and abroad [5-8]. With the further improvement of the Runge-Kutta algorithm and the further development of the neutral delay differential equation theory, many scholars have studied the delay differential equations and get some related results about oscillation [9-14]. People use a series of techniques and methods, such as calculation and reasoning, to study these equations and to obtain the oscillation conditions of the solution of the equation [10, 15-19]. How to get the oscillation criterion of the neutral delay differential equation model becomes the key and the difficult problem

Correspondence: luohongy1982@163.com

College of Mathematics and Statistics, Qujing Normal University, Qujing, China

Springer Open
[20, 21]. The Runge-Kutta algorithm and Riccati transform provide an effective and practical method for us to study the two-order neutral time-delay model.

In this paper, we study the dynamic characteristics of a class of second-order neutral delay models by using the Runge-Kutta algorithm. We have obtained some new oscillation criteria for a class of second-order neutral delay nonlinear differential equation models. These results promote and improve the known results in the literature.

\section{Model and methodology}

The vibration problems in engineering, cybernetics, communication technology, physics, and other fields can be represented by the neutral delay model differential equation model. For a long time, the problem of dynamics has been the concern of experts and scholars at home and abroad. To this end, the experts also set up some neutral delay model to study the vibration of engineering, automatic control, communication technology, and other practical problems. On the basis of the existing literature, this paper studies a class of engineering control problems, that is, a class of second-order neutral delay differential equations with the expression equation model: 


$$
\left(r(t) \phi_{\alpha}\left(z^{\prime}(t)\right)\right)^{\prime}+p(t) \phi_{\alpha}\left(z^{\prime}(t)\right)+f(t, x(\sigma(t)))=0, t \geq t_{0}
$$

where $z(t)=x(t)+c(t) x(\tau(t)), \quad \phi_{\alpha}(s)=|s|^{\alpha-1} s \quad$ and the following conditions are satisfied:

$\left(h_{1}\right) \exists q(t) \in C\left[t_{0}, \infty\right), f(t, x)$ sgn $x \geq q(t)|x|^{\beta}, \alpha$ and $\beta$ are constants.

$$
\begin{gathered}
\left(h_{2}\right) p(t), r(t) \in C\left(\left[t_{0}, \infty\right]\right), p(t) \geq 0, r(t)>0,-1<c(t)<0 \\
\left(h_{3}\right) \sigma(t) \in C^{1}\left(\left[t_{0}, \infty\right], R\right), \sigma(t)>0, \sigma^{\prime}(t)>0, \sigma(t) \leq t \\
\lim _{t \rightarrow \infty} \sigma(t)=\infty \\
\left(h_{4}\right) \int_{t_{0}}^{\infty} R^{-\frac{1}{\alpha}}(t) d t=+\infty, R(t)=E(t) r(t), E(t) \\
=\exp \int_{t_{0}}^{t} \frac{p(s)}{r(s)} d s .
\end{gathered}
$$

This model (1) has been widely used in engineering, automatic control, communication technology, physics, and other systems. By using Riccati transformation and computational reasoning, some new vibration criteria for two-order neutral delay differential Eq. (1) are obtained. These results promote and improve some of the wellknown results.

\section{Results and discussion}

In this paper, in order to study the vibration of the system (1), we will use the generalized Riccati transform method to study Eq. (1).

Lemma 1 Assume that $\left(h_{1}\right) \sim\left(h_{4}\right)$ holds, and $x(t)$ is an eventually positive solution of Eq. (2), then $z(t)>0, z^{\prime}(t)>$ 0 ,or $x(t) \rightarrow 0$.

Proof We Suppose $x(t)$ is an eventually positive solution of Eq. (2). If $z(t)>0$, we have

$$
\left(R(t) \phi_{\alpha}\left(z^{\prime}(t)\right)\right)^{\prime}+E(t) f(t, x(\sigma(t)))=0 .
$$

Then,

$$
\left(R(t) \phi_{\alpha}\left(z^{\prime}(t)\right)\right)^{\prime} \leq 0
$$

that is,

$$
\left(R(t)\left|z^{\prime}(t)\right|^{\alpha-1} z^{\prime}(t)\right)^{\prime} \leq 0
$$

$z^{\prime}(t)$ is eventually of one sign, that is, $z^{\prime}(t)>0$ or $z^{\prime}(t)<0$. Otherwise, if there exists $T$, such that $z^{\prime}(t)<0$ for $t \geq T$, then for arbitrary positive $K$, we have

$$
\begin{aligned}
& R(t)\left|z^{\prime}(t)\right|^{\alpha-1} z^{\prime}(t) \leq-R(T)\left(-z^{\prime}(T)\right)=-K<0 . \\
& -z^{\prime}(t) \geq\left(\frac{k}{R(t)}\right)^{1 / \alpha} .
\end{aligned}
$$

$$
0<z(t) \leq z(T)-K^{\frac{1}{\alpha}} \int_{T}^{t} R^{-\frac{1}{\alpha}}(s) d s \rightarrow-\infty .
$$

Therefore, $z^{\prime}(t)>0$.

If $z(t)<0$, then $x(t)$ is bounded. Otherwise, if $x(t)$ is unbounded, $\exists\left\{t_{n}\right\}_{n=1}^{\infty}$, such that $\lim _{n \rightarrow \infty} t_{n}=\infty$, let $x\left(t_{n}\right)$

$=\max _{s \in\left[T, x_{n}\right]}\{x(s)\}$; thus, $t_{n} \geq \tau\left(t_{n}\right) \geq T$.

$x\left(\tau\left(t_{n}\right)\right) \leq \max _{s \in\left[T, x_{n}\right]}\{x(s)\}=x\left(t_{n}\right)$

$<-c\left(t_{n}\right) x\left(\tau\left(t_{n}\right)\right)<x\left(\tau\left(t_{n}\right)\right)$.

Therefore, $x(t)$ is bounded.

$0 \geq \lim \sup _{t \rightarrow \infty} \sup z(t)$

$\left.\geq \lim \sup _{t \rightarrow \infty} x(t)+\lim \inf _{t \rightarrow \infty} c(t) x(t)\right)$

$\geq(1-c) \lim _{t \rightarrow \infty} \inf x(t)_{\geq 0}$.

Thus, $\lim _{t \rightarrow \infty} x(t)=0$.

Lemma 2 We suppose $x(t)$ is an eventually positive solution of Eq. (2), then

(1) $z(t)>t z^{\prime}(t)$;

(2) $\frac{z(t)}{t}$ is strictly decreasing eventually.

Proof Since $\left(R(t)\left(z^{\prime}(t)\right)^{\alpha}\right)^{\prime} \leq 0$, then $z^{\prime \prime}(t) \leq 0$. Let $g(t)=$ $z(t)-t z^{\prime}(t)$; we get $g^{\prime}(t)=-t z^{\prime \prime}(t)>0$ and we assert that $g(t)>0$ eventually. Otherwise, $g(t)<0$, so

$$
\left(\frac{z(t)}{t}\right)^{\prime}=-\frac{g(t)}{t^{2}}>0
$$

Thus, $\frac{z(t)}{t}$ is strictly increasing.

$\frac{z(\sigma(t))}{\sigma(t)} \geq \frac{z(\sigma(T))}{\sigma(T)}=b>0, t \geq T$.

We have $z(\sigma(t)) \geq b \sigma(t)$; thus,

$0<R(t)\left(z^{\prime}(t)\right)^{\prime}$

$$
\begin{aligned}
& \leq R(T)\left(z^{\prime}(T)\right)^{\alpha}-\int_{T}^{t} Q(s) z^{\beta}(\sigma(s)) d s \\
& \leq R(T)\left(z^{\prime}(T)\right)^{\alpha}-b^{\beta} \int_{T}^{t} Q(s) \sigma^{\beta}(s) d s \rightarrow-\infty .
\end{aligned}
$$

Then, $z(t)>t z^{\prime}(t)$, and $\frac{z(t)}{t}$ is strictly decreasing eventually.

Theorem 1 Assume that $\int_{T}^{t}\left[\rho(s) Q(s)\left(\frac{\sigma(s)}{s}\right)^{\beta}-\right.$ $\left.\frac{R(s)\left(\rho^{\prime}(s)\right)^{\lambda+1}}{(\lambda+1)^{\lambda+1}(m \rho(s))^{\lambda}}\right] d s=\infty$, then Eq. (2) is almost oscillatory.

Proof We suppose $x(t)$ is an eventually positive solution of Eq. (2); from Lemma 1, we have

$z(t)>0, z^{\prime}(t)>0$, or $x(t) \rightarrow 0$.

We define the function 


$$
w(t)=\frac{R(t)\left(z^{\prime}(t)\right)^{\alpha}}{z^{\beta}(t)} .
$$

If $\beta \geq \alpha$, we have

$$
\begin{aligned}
& w^{\prime}(t)=\frac{\left(R(t)\left(z^{\prime}(t)\right)^{\alpha}\right)^{\prime}}{z^{\beta}(t)}-\frac{\beta}{R^{1 / \alpha}(t)}[z(t)]^{\frac{\beta-\alpha}{\alpha}} w^{\frac{\alpha+1}{\alpha}}(t) \\
& \leq-Q(t)\left(\frac{\sigma(t)}{t}\right)^{\beta}-\frac{\alpha m_{1}}{R^{1 / \alpha}(t)} w^{\frac{\alpha+1}{\alpha}}(t) .
\end{aligned}
$$

where $m_{1}=\min \left\{1,[z(T)]^{\frac{\beta-\alpha}{\alpha}}\right\}$.

If $\beta<\alpha$, we have

$$
\begin{aligned}
& w^{\prime}(t) \leq-Q(t)\left(\frac{\sigma(t)}{t}\right)^{\beta}-\frac{\beta}{R^{1 / \beta}(t)}\left[z^{\prime}(t)\right]^{\frac{\beta-\alpha}{\beta}} w^{\frac{\beta+1}{\beta}}(t) \\
& \leq-Q(t)\left(\frac{\sigma(t)}{t}\right)^{\beta}-\frac{\beta m_{2}}{R^{1 / \beta}(t)} w^{\frac{\beta+1}{\beta}}(t) .
\end{aligned}
$$

where $m_{2}=\min \left\{1,\left[z^{\prime}(T)\right]^{\frac{\beta-\alpha}{\beta}}\right\}$.

Therefore, if $\beta<\alpha$ or $\beta<\alpha$, we have

$$
w^{\prime}(t) \leq-Q(t)\left(\frac{\sigma(t)}{t}\right)^{\beta}-\frac{\lambda m}{R^{1 / \lambda}(t)} w^{\frac{\lambda+1}{\lambda}}(t)
$$

where $\lambda=\min \{\alpha, \beta\}$. Let $A(t)=\frac{\lambda m}{R^{1 / \lambda(t)}}$; we have

$$
\begin{aligned}
& \int_{T}^{t} \rho(s) Q(s)\left(\frac{\sigma(s)}{s}\right)^{\beta} d s \leq-\int_{T}^{t} \rho(s) w^{\prime}(s) d s \\
& -\int_{T}^{t} \rho(s) A(s) w^{\frac{\lambda+1}{\lambda}}(s) d s \\
& \leq \rho(T) w(T)-\rho(t) w(t)+\int_{T}^{t}\left[\rho^{\prime}(s) w(s) d s-\rho(s) A(s) w^{\frac{\lambda+1}{\lambda}}(s)\right] d s \\
& \leq \rho(T) w(T)+\int_{T}^{t} \frac{\lambda^{\lambda} R(s)\left(\rho^{\prime}(s)\right)^{\lambda+1}}{(\lambda+1)^{\lambda+1}(\lambda m \rho(s))^{\lambda}} d s \\
& =\rho(T) w(T)+\int_{T}^{t} \frac{R(s)\left(\rho^{\prime}(s)\right)^{\lambda+1}}{(\lambda+1)^{\lambda+1}(m \rho(s))^{\lambda}} d s .
\end{aligned}
$$

We have

$$
\int_{T}^{t}\left[\rho(s) Q(s)\left(\frac{\sigma(s)}{s}\right)^{\beta}-\frac{R(s)\left(\rho^{\prime}(s)\right)^{\lambda+1}}{(\lambda+1)^{\lambda+1}(m \rho(s))^{\lambda}}\right] d s \leq \rho(T) w(T)<\infty .
$$

By the Lemma 1 and the Lemma 2 and the related theory of equation oscillatory, we get Eq. (2) is almost oscillatory.

\section{Conclusions}

In this paper, the second-order neutral delay nonlinear model is studied by combining the Runge-Kutta algorithm and the Riccati transformation method. We have obtained the oscillation criterion of the second-order neutral delay nonlinear differential equation model. Most of the literature mainly studied the situation $\alpha \geq \beta$ $[5-8,13-21]$. We not only studied the situation $\alpha \geq \beta$ but also studied the situation $\alpha<\beta$. We generalize the existing results and get the new oscillation criterion.

This second-order neutral delay differential equation describes the oscillation phenomena in the fields of engineering, control, communication, physics, and other fields. This indicates that oscillation in engineering, control and communication technologies will cause internal damage. We can predict the oscillation by the Runge-Kutta algorithm and the Riccati transform, in order to avoid the occurrence of oscillation in actual conditions such as engineering, control, communication technology and so on.

\section{Abbreviation}

Eq: Equation

\section{Acknowledgements}

The research presented in this paper was supported by the China National Natural Science Foundation, Yunnan Science and Technology Department of China, and Qujing Normal University, China.

\section{Funding}

The authors acknowledge the National Natural Science Foundation of China (grant 11361048), Yunnan Natural Science Foundation of China (grant 2017FH001-014), and Qujing Normal University Science Foundation of China (grant ZDKC2016002).

\section{Availability of data and materials}

The simulation code can be downloaded at literature [11], and it is applicable.

\section{Author's contributions}

$\mathrm{HL}$ is the only author of this article. By using the Runge-Kutta algorithm and Riccati transformation method, we study the dynamical properties of a class of two-order neutral delay nonlinear models and establish some new sufficient conditions. The author read and approved the final manuscript.

\section{Competing interests}

The author declares that he/she has no competing interests.

\section{Publisher's Note}

Springer Nature remains neutral with regard to jurisdictional claims in published maps and institutional affiliations.

Received: 20 March 2018 Accepted: 24 April 2018

Published online: 03 May 2018

\section{References}

1. MH Carpenter, D Gottlieb, S Abarbanel, WS Don, The theoretical accuracy of Runge-Kutta discretization for the initial-boundary value problem: a study of the boundary error. SIAM J.Sci.Comput 16, 1241-1252 (1995)

2. Q Zhang, Third order explicit Runge-Kutta discontinuous Galerkin method for linear conservation law with inflow boundary condition. J. Sci. Comput. 46(2), 294-313 (2011)

3. Q Zhang, CW Shu, Error estimates to smooth solution of Runge-Kutta discontinuous Galerkin methods for scalar conservation laws. SIAM J. Numer. Anal. 42, 641-666 (2004)

4. B Cockburn, CW Shu, Runge-Kutta discontinuous Galerkin methods for convection-dominated problems. J.Sci. Comput 16, 173-261 (2001)

5. ME Elmetwally, SH Taher, HS Samir, Oscillation of nonlinear neural delay differential equations. J. Appl. Math. \& Computing 21(1), 99-118 (2006)

6. $\quad \mathrm{P} \mathrm{Hu}, \mathrm{CM}$ Huang, Analytical and numerical stability of nonlinear neural delay integro-differential equations. Journal of the Franklin Institutc 348 1082-1100 (2011) 
7. S Zhang, Q Wang, Oscillation of second-order nonlinear neutral dynamic equations on time scales. AppliedMathematics and Computation 216, 2837-2848 (2010)

8. Q Li, R Wang, F Chen, TX Li, Oscillation of second-order nonlinear delay differential equations with nonpositive neutral coefficients. Advances in Difference Equations 35, 1-7 (2015)

9. J Liu, HY Luo, X Liu, Oscillation criteria for half-linear functional differential equation with damping. Therm. Sci. 18(5), 1537-1542 (2014)

10. T Candan, Oscillatory behavior of second order nonlinear neutral differentia equations with distributed deviating arguments. Appl. Math. Comput. 262, 199-203 (2015)

11. HY Luo, J Liu, X Liu, Oscillation behavior of a class of new generalized Emden-Fowler equations. Therm. Sci. 18(5), 1567-1572 (2014)

12. RP Agarwal, CH Zhang, TX Li, Some remarks o nonlinear neutral $n$ of second order neutral differential equations. Appl. Math. Comput. 274, 178-181 (2016)

13. J Dzurina, LP Stavroulakis, Oscillation criteria for second-order delay differential equation. Appl. Math. Comput. 174, 1636-1641 (2003)

14. FW Meng, R Xu, Oscillation criteria for certain even order quasi-linear neutral differential equations with deviating arguments. Appl. Math. Comput. 190, 458-464 (2007)

15. ZW Zheng, X Wang, HM Han, Oscillation criteria for forced second order differential equations with mixed nonlinearities. Appl. Math. Lett. 22, 10961101 (2009)

16. QX Zhang, SH Liu, L Gao, Oscillation criteria for even-order half-linear functional differential equation. Appl. Math. Lett. 24, 1709-1715 (2011)

17. ZL Han, TX Li, CH Zhang, Y Sun, Oscillation criteria for certain second-order nonlinear neutral differential equations of mixed type. Abstr. Appl. Anal. 387483, 1-9 (2011)

18. HD Liu, FW Meng, PC Liu, Oscillation and asymptotic analysis on a new generalized Emden-Fowler equation. Appl. Math. Comput. 219, 2739-2748 (2015)

19. SH Liu, QX Zhang, YH Yu, Oscillation of even-order half-linear differential equation with damping. Computers and Mathematics with Applications 61, 2191-2196 (2011)

20. CJ Zhang, TT Qin, J Jin, An improvement of the numerical stability results for nonlinear neutral delay-integro-differential equations. Appl. Math. Comput 215, 548-556 (2009)

21. JJ Zhao, Y Cao, Y Xu, Legendre spectral collocation methods for volterra delay-integro-differential equations. J. Sci. Comput. 67(3), 1110-1133 (2016)

\section{Submit your manuscript to a SpringerOpen ${ }^{\circ}$ journal and benefit from:}

- Convenient online submission

- Rigorous peer review

- Open access: articles freely available online

- High visibility within the field

Retaining the copyright to your article

Submit your next manuscript at $>$ springeropen.com 